\title{
Astrocytoma of the optic nerve and chiasm associated with microphthalmos and orbital cyst
}

\author{
JOHN BONNER* AND GARL H. IDE
}

From the Departments of Surgery-Neurosurgery and Ophthalmology, University of Missouri School of Medicine, Columbia, Missouri, U.S.A.

An astrocytoma of the optic nerve is a relatively rare, slow-growing tumour which arises in the intraorbital or intracranial segment of the nerve. Its occurrence in association with microphthalmos and congenital cyst has to our knowledge not been described previously.

\section{Case report}

A 2-day-old male infant was seen in consultation by the Ophthalmology Service at the University of Missouri School of Medicine. The patient was the product of a normal pregnancy and delivery. There was no family history of congenital abnormalities.

\section{Examination}

The right eye was normal. The left lid fissure was smaller than the right. A soft cyst, that transilluminated readily, occupied the left orbit (Fig. I). The remainder of the physical examination was within normal limits.

The baby was admitted to hospital 4 months later for removal of what appeared clinically to be a congenital cystic eye. The interim history given by the mother revealed that the cyst enlarged when the infant cried. This observation was verified by us and led us to consider the possibility of a communication between the cyst and the subarachnoid space.

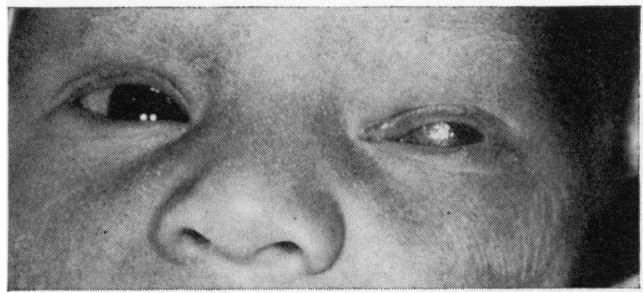

FIG. I Translucent cyst occupying much of left orbit. Appearance 2 days after birth

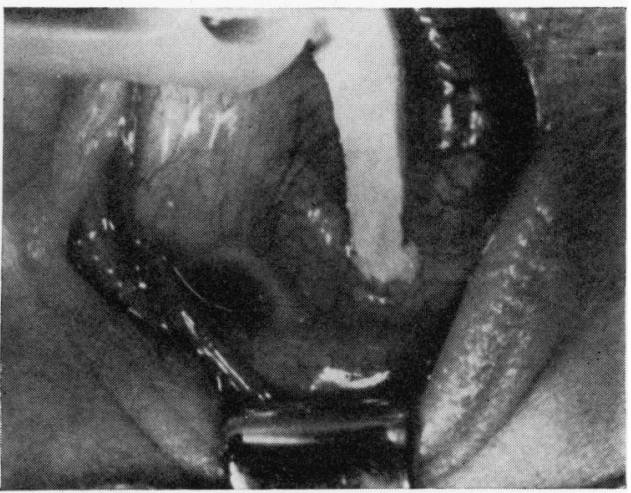

FIG. 2 Microphthalmic eye attached to inferior portion of cyst (the cyst has been rotated upward with a sponge)

Address for reprints: Prof. Carl H. Ide, M.D., Department of Ophthalmology, University of Missouri School of Medicine, 807 Stadium Road, Columbia, Missouri 65201, U.S.A.

*Address: 5151 North Palm Avenue, Suite 890, Fresno, California 93705, U.S.A. 
After insertion of the lid speculum into the left conjunctival sac and upward rotation of the cyst, a microphthalmic eye was noted inferiorly (Fig. 2). The conjunctiva was opened and the microphthalmic eye and the cyst were removed in one piece (Fig. 3). A persistent cerebrospinal fluid leak from the posterior portion of the socket occurred during this procedure. The neurosurgical staff was consulted and it was decided to pack the anterior area of the orbit with gauze and place a pressure dressing on the eye lids. The patient was transferred to the Neurosurgical Service.

\section{Progress}

The cerebrospinal fluid leak persisted despite the orbital dressing, head elevation, and lumbar punctures with removal of cerebrospinal fluid three or four times a day. Systemic antibiotics were given. There was no evidence of meningitis at any time.
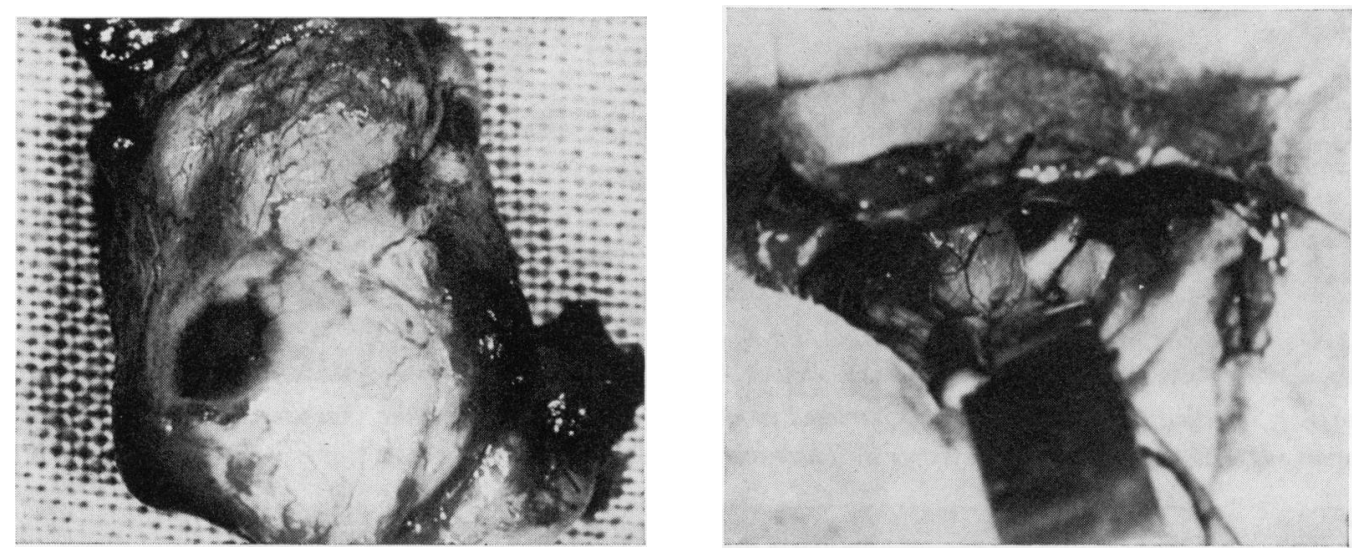

FIG. 3 Specimen consisting of microphthalmic eye, orbital cyst, and astrocytoma

FIG. 4 Left optic nerve consists of a cystic structure continuous with the chiasm. Right optic nerve appears normal.

\section{Histological examination}

An astrocytoma was found in the posterior part of the specimen. Pneumoencephalography was done to outline the possible posterior extent of the glioma. The results were reported normal.

\section{Second operation}

On the twelfth postoperative day, a left frontal craniotomy was performed. The left optic nerve consisted of a cystic structure 6 to $7 \mathrm{~mm}$. in width (Fig. 4). There was no apparent evidence of communication with the ventricular system, as it did not collapse with cerebrospinal fluid drainage. The cyst was in continuity with the optic chiasm. After amputation of the cystic left optic nerve at the junction with the optic chiasm, gross examination of the specimen showed neural tissue to be most prominent in the medial and lateral aspects.

Protein determination of the cyst fluid was $22.5 \mathrm{mg}$. per cent., the initial CSF protein being $60 \mathrm{mg}$. per cent.

Pathological examination revealed that the specimen also contained tumour tissue identified as astrocytoma (Figs 5 and 6, overleaf).

The optic chiasm appeared normal to inspection, although its involvement by the glioma was a distinct possibility. Since vision with the right eye seemed unimpaired, and cure was uncertain if the optic chiasm and proximal tracts were excised, no further resection was attempted. The right optic nerve appeared normal.

The remainder of the left intraorbital contents was removed during the same procedure to eliminate the possibility of residual tumour tissue being left behind. A muscle plug was inserted into the optic foramen and acrylic was placed over it from both the intracranial and orbital aspects.

\section{Progress}

On the second postoperative day cerebrospinal fluid again leaked from the left orbit. The leakage persisted despite serial lumbar punctures, with maximum fluid removal on each occasion. 


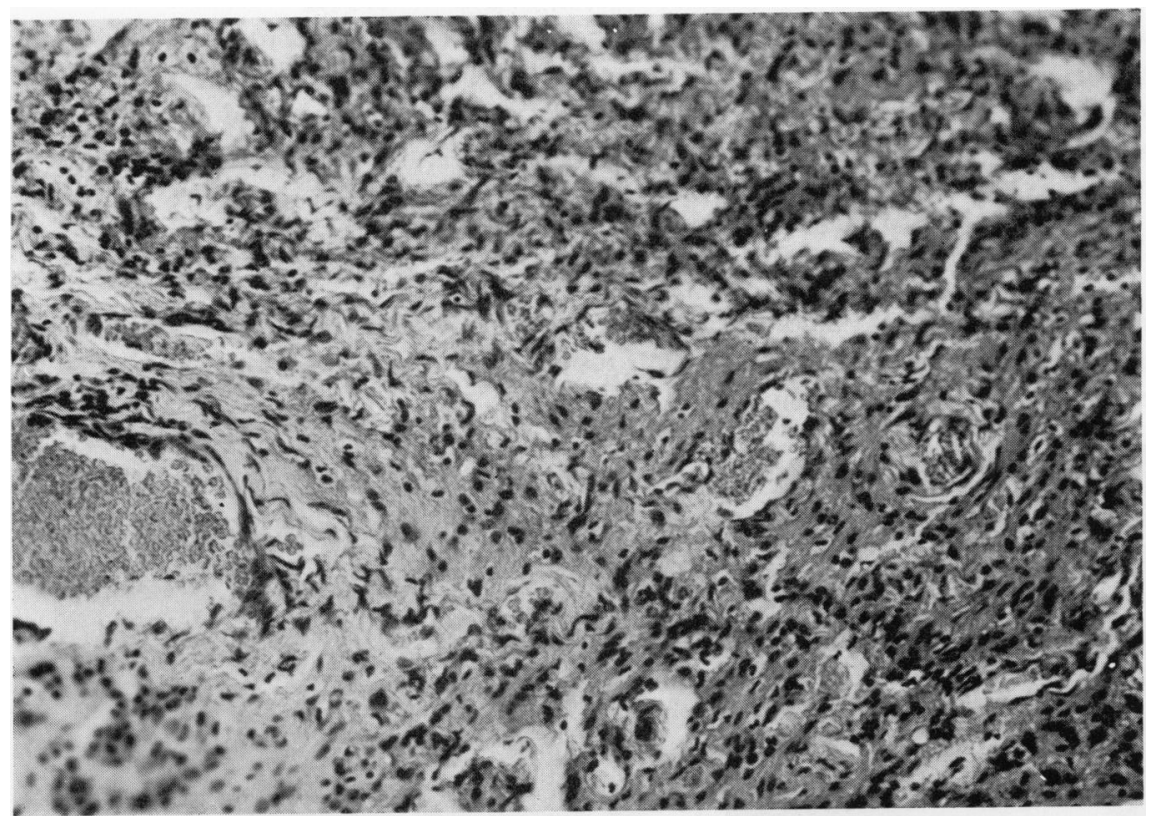

FIG. 5 Section of tumour shows an increased number of astrocytes with mature characteristics and occasional areas suggestive of spongioblastic elements. There are abundant glial fibres. $\times 125$

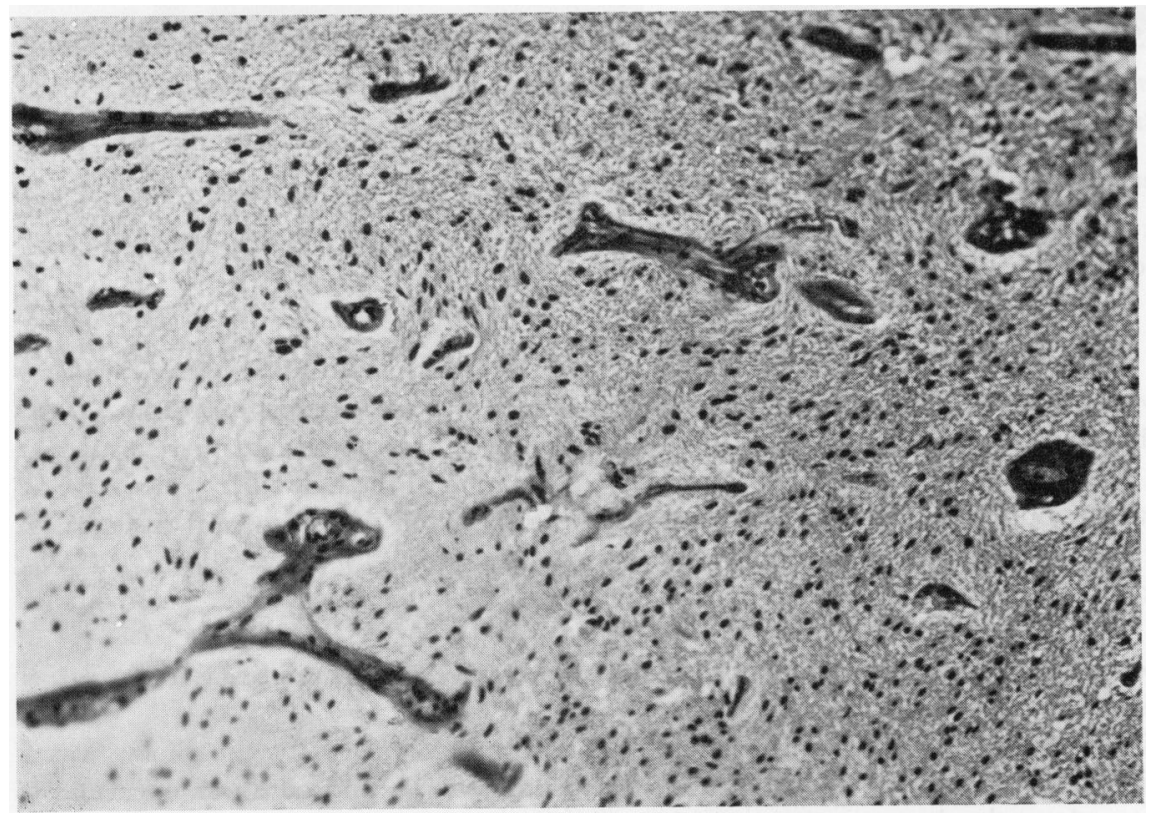

FIG. 6 Specimen from cystic optic nerve removed at second operative procedure shows an increased number of mature astrocytes and rather prominent capillaries. $\times 125$

\section{Third operation}

7 days after the craniotomy, under Ketamine anaesthesia, a new plug of temporalis muscle was placed into the optic foramen. A left temporalis muscle- and fascial flap was rotated into the orbit to reinforce the muscle plug. No further orbital cerebrospinal fluid leak occurred. 
Result

Serial lumbar punctures were again performed for approximately 12 days. The patient was discharged on the 43 rd hospital day with good vision in the right eye and no evidence of left orbital spinal fluid leak or other neurological deficits. The radiation therapy consultant elected not to treat the chiasmatic region because of the mature glioma elements in the histology.

\section{Discussion}

Optic nerve gliomas occur infrequently, the incidence in a series reported by Martin and Cushing (1923) being 0.84 per cent. in a study of 826 intracranial tumours. According to Fowler and Matson (1957), 75 per cent. of optic nerve gliomas are found in children below the age of 12 years. The origin of the glioma may be the region of the optic foramen; it can extend in both directions (Mohan and Sen, 1970) and often involves both intracranial and intraorbital contents, as in our case.

The astrocytoma is the most common type of optic nerve glioma. Oligodendroglial elements, however, may also be present in the tumour (Russell and Rubinstein, 1963). The astrocytic configuration is frequently of spongioblastoma type and can be expected to be more sensitive to radiation than cytologically more mature tumours. Taveras, Mount, and Wood (1956) stated that radiation therapy could be effective in the treatment of optic gliomas and that the prognosis was somewhat worse when the chiasm was involved.

Hoyt and Baghdassarian (1969) documented the previously widely held opinion (Hudson, I912; Posner and Horrax, I948) that even chiasmal and hypothalamic involvement could be compatible with long survival. Their series seemed to support the impression, whether real or apparent, that the tumours often appeared to be quiescent after exposure and surgical biopsy. They felt that the prognosis was good for vision and that neither surgical excision nor radiation therapy was justified except for relief of proptosis.

The occurrence of an astrocytoma of the optic nerve associated with microphthalmos and orbital cyst appears to be unique. Its intimate association with obvious orbital developmental aberrations suggests that the tumour was of developmental origin. As the tumour appeared to involve the chiasm and sight was present in the right eye, an attempt to excise the tumour completely did not appear to be justified.

\section{Summary}

A case of astrocytoma of the optic nerve and chiasm presented clinically as a congenital cystic eye. It is suggested that the tumour development was part of the developmental process responsible for the gross global deformities.

We should like to thank Roy J. Wilson, M.S., for the photography and E. C. Alvord, Jr.. M.D., for reviewing the histological slides.

\section{References}

FOWLER, F. D., and MATSON, D. D. (1957) 7. Neurosurg., 14, 515

hOYT, W. F., and BaGHDASSARIAN, s. A. (I969) Brit. J. Ophthal., 53, 793

HuDson, A. c. (1912) Roy. Lond. ophthal. Hosp. Rep., 18, 317

MARTin, P., and cushing, H. (1923) Arch. Ophthal. (N.Y.), 52, 209

MOHAN, H., and SEN, D. K. (1970) Brit. F. Ophthal., 54, 284

POSNER, M., and hORRAX, G. (1948) Arch. Ophthal. (Chicago), 40, 56

RUSSEll, D. S., and RUBinsteIn, L. J. (1963) "Pathology of Tumours of the Nervous System", p. I92. Arnold, London

TAVeras, J. M., MOUNT, L. A., and wood, E. H. (I956) Radiology, 66, 5 I 8 